\title{
Credible Online News? Yes or No
}

\author{
Akmar Hayati Ahmad Ghazali, Rahmawati Nurdin, Sharil Nizam \\ Universiti Putra Malaysia, Selangor, Malaysia
}

\begin{abstract}
Dissemination of information medium are no longer limited to newspapers, television and radio but is extending to the online news. The number of online news readers is rapidly increasing along with the popularity of the Internet. However, only sources that emphasizes the element of credibility will be accepted by the readers. This study was conducted to determine the credibility of online news; to identify the relationship between online news credibility and youth acceptance. Using a quantitative approach, a total of 400 youth selected to participate in the study out of the 68,000 population in Selangor. The data was analyzed using Statistical Package for Social Science (SPSS) version 21.0. This study shows that a group of young women were the common group who seek and read online information. Based on the findings too, online news in Malaysia are less credible. Although the online news is less credible, the results shows that youth read online news because the contents are current and up to date. Further, result of the Pearson's correlation test shows that the more credible elements available in online news, the more that medium is accepted by youth.
\end{abstract}

Keywords: acceptance, credibility, youth, online news, information

\section{Background}

The world of communication technology has changed the pattern of information searching by the reader. They no longer only depend on traditional media but also the new media such as the Internet. Through Internet, information can be obtained and read anywhere by using smart devices. Hence, this research was carried out to achieve the objectives of the study; to determine the credibility of online news; to identify the relationship between online news credibility and youth acceptance.

\section{Media and Credibility}

Studies on media and credibility have been initiated by Hovland and Weiss (1953), entitled The influence of source credibility on communication effectiveness. This study was conducted to find out the factors that influence audiences' acceptance as the effect of media exposure that is frequently used. Through the study, they identified factors that influence audiences' acceptance to media is the infusion of credibility elements. Later, Lee (1978) continued the studies on Credibility of newspapers and tv news. It is said that, this study is among the first to be created aims to investigate about newspapers and television news credibility. The results of his research found out that credibility is the main factor of readers' acceptance towards newspapers and TV news. However, studies that has opened the eyes of many other researchers is a study conducted by Gaziano and

\footnotetext{
Akmar Hayati Ahmad Ghazali, Ph.D., Communication Department, Faculty of Modern Languages and Communication, Universiti Putra Malaysia.

Rahmawati Nurdin, Communication Department, Faculty of Modern Languages and Communication, Universiti Putra Malaysia.

Sharil Nizam, Ph.D., Malay Language Department, Faculty of Modern Languages and Communication, Universiti Putra Malaysia.
} 
McGrath (1986), titled Measuring the concept of credibility. Both of these researchers have established a scale that measures the credibility. There are 12 components of credibility which are, trustworthiness, currency, unbiased, fairness, completeness, objectivity, honesty, up-to-date, believability, balance, accuracy and timeliness. Based on these 12 components, it showed readers have their reasons to read and accept the media. As a conclusion, credibility is closely linked to the perspective of an individual. If that individual consider the media as reliable, they will accept the media. Therefore, credibility is a concept that should be properly considered in studies related to the receipt of information.

\section{Online News Publication}

The emergence of the Internet and the involvement of the press in reporting news in the Internet raises some new terms which are sometimes confusing. Dominick (1996), introduces some new terms such as: online news, online papers, electronic news and digital newspapers in describing the change in the method of newspaper presentations from ink and paper to the Internet. However, Ab. Jalil (2010), defines the online news as a fully Internet news portal without a printed version like Malaysiakini (www.malaysiakini.com) and Mstar (www.mstar.com.my). Online news is often updated several times a day, including changes to the main title. As a result of constantly updated information, the number of online news readers is rapidly increasing along with the popularity of the Internet (Chung, Nam, \& Stefanone, 2012). In fact, readers are getting less interested in reading the printed newspaper due to convenient factor (Berthon, Pitt, \& Watson, 1996), more credible than the printed press (Johnson \& Kaye, 2002), online news report the information which were not disclosed by the mainstream printed press (Johnson \& Kaye, 2004).

\section{Online News Credibility}

In this era of information technology, information can be obtained from various sources. Dissemination of information medium are no longer limited to newspapers, television and radio but is extending to the online news. This publication is used not only to search for information but the users could interact with each other while reading. However, only sources that emphasizes the element of credibility will be accepted by the readers. (Elliot \& Culver, 1992).

What is credibility? Eisend (2006) stated that credibility is an individual perceptions about the truth of the information and the reliability of the information (Fogg, Marshall, \& Laraki, 2001; Tseng \& Fogg, 1999). Based on these interpretations, it suggests that readers assume that the information presented by the media is true and reliable. Wathen and Burkell (2002) pointed out that credibility is one of the criteria used to measure information. As long as the information transmitted is credible, the society will still accept the information. Researchers have different opinions about the credibility of the online news. Flanagin and Metzger (2000), states that information on the Internet is reliable, but not as credible as the information in the printed press sourced from trusted sources, such as the government (Mohd Asri, 2002), group of experts and the industry (Cozma, 2006). Falanagin and Metzger findings are agreed by Mehrabi, Hassan, and ALİ (2009), which revealed that television news is more reliable than online news. Poler, Erjavec, and Štular (2010) also believes that majority of journalists still believe that traditional media is the most reliable because of its credibility. Unlike Nozato (2002), findings which stated that online news has high credibility because it is influenced by elements such as timeliness, depth, reputation, and accuracy. These findings are supported by Rasha, Garrison, Salwen, Driscoll, and Casey (2002), stating that the online media is credible because it is more precise about the timeliness and impartiality. 
In fact Cassidy (2007) also agrees that online news has credibility and are more reliable. Normah, Faridah, Mus Chairil, and Mohd. Helmi (2010), also believes that online news has credibility because of the current and unbiased news. Azmah and Samsudin (2013), also felt that online publishing is fairer and has a fact depth and the news published shows the union by not focusing only on certain group. While Ab. Hamid, Fadzli, Wan Solihin, and Wan Abd. Aziz (2014), stated that online information such as blogs are accepted as one of the information sources because of its credibility.

\section{Online News Acceptance}

Gardner and Amoroso (2004), explains that acceptance is closely related to perceived usefulness. Youth believe after using a technology system, it will benefit them such as increasing and improving their performance. The second factor is perceived ease of used. This factor assumes that when they use a technology system, it will affect them and they will be more proficient, easily understood. The third is the attitude towards using technology. Through these factors youth tend to have positive attitude and believe that the use of technology will increase their productivity and performances. The fourth factor is behavioral intention to use. This factor measures the seriousness of the person's intention to do something as a result of using a system. The fifth is perceived complexity which refers to the obstacles and problems for users when they use the technology.

According to Kloping and McKiney (2004), a desire to find information online is influenced by perceived usefulness. Young people believe that after the use of a technology system, it would be beneficial to them such as it will improve their performances. They will try out an application provided whether it is convenient or not and thus affect a user to continue using the system or to stop using it. However, a study by Ika and Mohd Helmi (2013), found that perceived ease of use and perceived usefulness are the factors that influence youth to accept information through online media. Ab. Hamid et al. (2014) states readers accepts blogs because of the responses to the amenities in using blogs, affect one's decision to accept blogs as one of the information channels.

\section{Methods}

This research use quantitative approach by means of surveys using questionnaires. A total of 400 youth selected to participate in the study out of the 68,000 population in Selangor based Yamane (1967), formula. The selection of respondents uses two sampling techniques which are easy sampling and purposive sampling based on the characteristics determined by the researchers according to the research objectives. For instrument that measures the credibility, researchers adapt and improve the questionnaire that was formed by Gaziano and McGrath (1986). As for the instrument that measures the acceptance, researchers adapt and improve the questionnaire, which was formed from the Development of an Instrument to Measure the Acceptance of Internet Technology by Consumers by Gardner and Amoroso (2004), stressed that this instrument is suitable to be use when assessing the acceptance of mass media technologies such as the Internet. All data were analyzed through statistics using SPSS version 21.0. Two statistical procedures were used, namely descriptive statistics and statistical inference. Descriptive statistics aims to identify the percentage, min, average, and standard deviation. While statistical inference describes the relationship between the variables studied. In statistical inference, data were tested by Pearson Product-Moment correlation coefficient test.

\section{Results}

\section{Respondent Demographics}

Table 1 showing youths aged 19 to 24 years $(89.9 \%)$ is exceeding respondents aged 37 years to 42 years 
$(1.3 \%)$. It shows that online news is most widely read by the youth. While in terms of gender, 55 percent of the sample were women. Based on the findings, it was concluded that a group of young women were the common group who seek and read online news.

Table 1

Respondent Distribution According to Demography $(n=400)$

\begin{tabular}{lll}
\hline Profile & Frequency & Percentages \\
\hline Age & & \\
\hline $19-24$ years & 359 & 89.9 \\
$25-30$ years & 24 & 6.1 \\
$31-36$ years & 13 & 2.7 \\
$37-42$ years & 4 & 1.3 \\
\hline Gender & & \\
\hline Female & 22 & 55.5 \\
Male & 178 & 44.5 \\
\hline
\end{tabular}

\section{Online News Credibility}

To determine the credibility of online news, researchers have used the mean scores of the four stages of the credibility factor categorized into low, medium and high. The highest mean score (3:00 - 4:00) shows the online newspapers have credibility. Medium score $(2.00-2.99)$ indicates online newspaper is less credible. While the lowest score $(1.00-199)$ show that the medium is not credible (see Table 2).

Table 2

Online Newspaper Credibility Measurement Score

\begin{tabular}{ll}
\hline Stage & Mean Score \\
\hline Low & $1.00-1.99$ \\
Medium & $2.00-2.99$ \\
High & $3.00-4.00$ \\
\hline
\end{tabular}

Table 3

Online Newspapers Credibility Mean Score

\begin{tabular}{lll}
\hline Credibility Dimensions & Mean & Std Deviation \\
\hline Currency & 3.20 & 0.55 \\
Up-to-date & 3.14 & 0.52 \\
Timeliness & 2.84 & 0.61 \\
Trustworthiness & 2.63 & 0.53 \\
News by evidence & 2.35 & 0.79 \\
Completeness & 2.33 & 0.58 \\
Unbiased & 2.32 & 0.61 \\
Fairness & 2.21 & 0.80 \\
True & 2.19 & 0.73 \\
Accuracy & 2.14 & 0.72 \\
Balance & 1.99 & 0.73 \\
Not Exaggerated & 1.83 & 0.69 \\
Overall & 2.54 & 0.35 \\
\hline
\end{tabular}

Notes. None (<1), Low (1.00 - 1.99), Medium (2.00 - 2.99), High $(3.00-4.00)$.

Table 3 shows the overall mean scores of online credibility is 2.54 with the standard deviation of 0.35 . This study shows that online newspaper in Malaysia are less credible. In the same time, the study also identified 
the dimensions of online newspapers credibility. Through the analysis, Table 3 had a high mean score because of its current news (3.20) and online news is the latest one (3.14). Based on the mean score, it shows that youth read online news because it is current and up to date. This finding supports a study conducted by Normah et al. (2010), who argued that the youth read the online newspaper as influenced by recent and current issues.

\section{Relationship Betwee Online News Credibility and Youth Acceptance}

Table 4 shows that there is a positive and significant relationship between credibility and acceptance despite the moderate strength of the relationship $(r=0.41)$. The result of this study indicated that, the more credible elements available in online news, the more that medium is accepted by youth. This suggests that the generation Y, always in need of information and credible news. So based on Diffusion of Innovation Theory (TDI), which became the core theory of this study indicate that when online news implement the credibilities, it will affect the readers' acceptance towards it.

Table 4

Relationship between Credibility and Acceptance $(n=400)$

\begin{tabular}{llc}
\hline \multirow{2}{*}{ Credibility } & \multicolumn{2}{c}{ Acceptance } \\
\cline { 2 - 3 } Currency & $r$ & $P$ \\
Up-to-date & 0.21 & 0.00 \\
Timeliness & 0.27 & 0.00 \\
Trustworthiness & 0.27 & 0.00 \\
News by evidence & 0.16 & 0.00 \\
Completeness & 0.11 & 0.05 \\
Unbiased & 0.17 & 0.00 \\
Fairness & 0.20 & 0.00 \\
True & 0.06 & 0.31 \\
Accuracy & 0.15 & 0.01 \\
Balance & 0.21 & 0.00 \\
Not Exaggerated & 0.02 & 0.63 \\
Overall & 0.06 & 0.26 \\
\hline
\end{tabular}

Note. Correlation is significant at level $0: 01$ (2-tailed).

As stated earlier, credibility is divided into 12 dimensions. Each of these dimensions were also analyzed to determine their relationship with the acceptance of youth. The results (see Table 4) show that there is a positive and significant relationship between currency, timeliness and up-to-date with the acceptance despite the poor strength of the relationship. The results of this study showed that the main factor is the youth accepted online news is because of the up-to-date, timeliness, and currency factors. Is the information they received is slow, they consider that the information is a bit outdated and has no credibility. This suggests that youth need appropriate information reached them swiftly.

The second interesting finding in this study is the balance report factor between the government and the opposition apparently does not really influenced youth in accepting the online news. Whether reports written are balanced or not, they still continue to accept the online newsp based on other elements of credibility provided. To keep on convincing the youth so that they continue to browse the online newspaper, online news providers should constantly update the information and news promptly. 


\section{Conclusion and Suggestion}

Online news is the source of information that publishes a variety of information. Youth is a group of people who is smart in controlling the technology. Not only they know the emergence of new technology, they also know how to handle the technology. Instead of reading only that news, they also read the variety of information in the online news. And now, they seek information online as an impact of using those technologies. However, the youth acceptance towards the information are varied and influenced by the credibility factors. Based on the findings, online news in Malaysia are less credible. They seek information actively through medium which always provided the latest, current and timeliness news for information can be search through their fingertips. But the youth must wisely choose the useful, helpful and credible information. It can also be concluded that the online news have contains many elements of credibiliy such as the trustworthiness, currency, unbiased, fairness, completeness, objectivity, honesty, up-to-date, believability, balance, accuracy and timeliness. All the online news should provide all these elements. Therefore, the main objective of the online news is to disseminate a variety of information can be achieved. It is hope that in the future research on this matter would add some study methods to get more robust findings, such as using interviews. By this method the researchers will be able to establish their own instruments corresponding to the local communities context

\section{References}

Ab. Hamid, A., Fadzli, A., Wan Solihin, W. A., \& Wan Abd. Aziz, W. M. A. (2014). Penerimaan blog sebagai medium agama dalam kalangan pelajar ipta di Malaysia (Blog acceptance as a religion medium among universities students in Malaysia). Proceeding of the International Conference on Arabic Studies and Islamic Civilization iCasic 2014 (e-ISBN 978-967-11768-4-9). Kuala Lumpur, Malaysia.

Ab. Jalil, A. B. (2010). Internet newspapers publishing in Malaysia: Focus on Utusan Malaysia (Unpublished Master dissertation, Universiti Malaya, Kuala Lumpur).

Azmah, A. W., \& Samsudin, A. R. (2013). Kredibiliti media dan penyertaannya dalam pengdemokrasian maklumat di Malaysia (Media credibilitiy and participation in a democratised media environment in Malaysia). Malaysian Journal of Communication, 29(1), 141-160.

Berthon, P., Pitt, L. F., \& Watson, R. T. (1996). The world wide web as an advertising medium. Journal of Advertising Research, 36(1), 43-54.

Cassidy, W. P. (2007). Online news credibility: An examination of the perceptions of newspaper journalists. Journal of Computer-Mediated Communication, 12(2), 478-498.

Chung, C. J., Nam, Y., \& Stefanone, M. A. (2012). Exploring online news credibility: The relative influence of traditional and technological factors. Journal of Computer-Mediated Communication, 17(2),171-186.

Cozma, R. (2006). Source diversity increases credibility of risk stories. Newspaper Research Journal, 27(3), 8-21.

Eisend, M. (2006). Source credibility dimensions in marketing communication-A generalized solution. Journal of Empirical Generalisations in Marketing Science, 10(2), 2-33.

Elliott, D., \& Culver, C. (1992). Defining and analyzing journalistic deception. Journal of Mass Media Ethics, 7(2), 69-84.

Flanagin, A. J., \& Metzger, M. J. (2000). Perception of internet information credibility. Journalism \& Mass Communication Quarterly, 77(3), 515-540.

Fogg, B. J., Marshall, J., \& Laraki, O. (2001). What makes web sites credible? A report on a large quantitative study. Retrieved from https://www.webcredibility.org

Gardner, C., \& Amoroso, D. L. (2004). Development of an instrument to measure the acceptance of internet technology by consumers. Proceedings from Prosiding ke-37 International Conference on System Sciences (pp. 1-10). Los Alamitos, CA: IEEE Computer Society.

Gaziano, C., \& McGrath, K. (1986). Measuring the concept of credibility. Journalism Quarterly, 63(3), 451-463.

Hovland, C. I., \& Weiss, W. (1953). The influence of source credibility on communication effectiveness. Public Opinion Quarterly, 15(4), 635-650. 
Ika, A., \& Mohd, H. (2013). Penerimaan media sosial: Kajian dalam kalangan pelajar universiti di Palembang (Social media acceptance: A research amongst university students in Palembang). Malaysian Journal of Communication, 29(2), 125-140.

Johnson, T. J., \& Kaye, B. K. (2002). Webelievability: A path model examining how convenience and reliance predict online credibility. Journalism \& Mass Communication Quarterly, 79, 619-642.

Johnson, T. J., \& Kaye, B. K. (2004). Wag the blog: How reliance on traditional media and the Internet influence credibility perceptions of weblogs among blog users. Journalism \& Mass Communication Quarterly, 81(3), 622-642.

Kloping, I. M., \& McKiney, E. (2004). Extending the technology acceptance model and the task-technology fit model to consumer e-commerce. Information Technology, Learning, and Performance Journal, 22(1), 35-48.

Lee, R. S. H. (1978). Credibility of newspaper and tv news. Journalism Quarterly, 55(2), 282-287.

May, H. (2004). Making statistics more meaningful for policy research and program evaluation. American Journal of Evaluation, 25(4), 525-540.

Mehrabi, D., Hassan, M. A., \& ALİ, M. S. (2009). News media credibility of the internet and television. European Journal of Social Sciences, 11(1), 136-148.

Mohd Asri, M. (2002). Pengaruh golongan elit pemerintah dalam pemaparan berita-berita etnik: Analisis kandungan terhadap pelaporan berita akhbar utusan malaysia dan berita harian sejurus sebelum dan selepas pilihanraya umum ke-10 Malaysia (The effect of the ruling elites in the portrayal of ethnic news: Content analysis of Utusan Malaysia and Berita Harian news reporting before and after the 10th Malaysia general election) (Unpublished Thesis, Universiti Sains Malaysia, Minden, Pulau Pinang).

Normah, M., Faridah, I., Mus Chairil, S., \& Mohd. Helmi, A. R. (2010). Persepsi khalayak terhadap kredibiliti media di Malaysia (Audience perception on media credibility in Malaysia). Journal of Social Sciences and Humanities, 5(2), 153-160.

Nozato, Y. (2002). Credibility of online newspapers. Retrieved from http://www.inma.org/subscribers/papers/2002-nazato.pdf

Poler, M. K., Erjavec, K., \& Štular, K. (2010). Credibility of traditional vs. online news media: A historical change in journalists' perceptions?. Media. Geol, 16(1), 113-130.

Rasha, A. A., Garrison, B., Salwen, M., Driscoll, P., \& Casey, D. (2000). The credibility of newspapers, television news, and online news. Retrieved from http://www.com.miami.edu/car/miamibeach1.pdf

Tseng, S., \& Fogg, B. J. (1999). Credibility and computing technology. Communications of the ACM, 42(5), 39-44.

Wathen, C. N., \& Burkell, J. (2002). Believe it or not: Factors influencing credibility on the Web. Journal of the American Society for Information Science and Technology, 53(2), 134-144.

Yamane, T. (1967). Elementary sampling theory. Englewood Cliffs, NJ: Prentice-Hall. 